\title{
Modelling farmer's crop choice with production externalities. The case of cultivation of rye in Finland
}

\author{
Antti Miettinen ${ }^{1)}$ and Anni Huhtala ${ }^{2)}$ \\ ${ }^{1)}$ MTT Agrifood Research Finland, Economic Research, Luutnantintie 13, 00410 Helsinki, \\ antti.miettinen@mtt.fi \\ ${ }^{2)}$ MTT Agrifood Research Finland, Economic Research, Luutnantintie 13, 00410 Helsinki, \\ anni.huhtala@mtt.fi
}

\section{Introduction}

Cultivation of rye causes several positive environmental externalities. Winter cereal fields have fewer weeds than spring cereal or hayfields (Mukula et al. 1969, Raatikainen and Raatikainen 1974, Raatikainen et al. 1978). Therefore the need for herbicide use is smaller in rye fields than in spring cereal fields, and rye's shoot offers vegetation to brown hares, partridges and pheasants from autumn till spring (Tiainen 1996, Tiainen and Pakkala 1996, Tiainen and Pankakoski 1996). Furthermore, since the arable area under rye in Finland has typically been less than 3\% of the total cereal area, an increase in cultivation of rye would enhance crop diversity which may in turn provide a buffering effect against losses to diseases and pests (Collins and Hawtin 1999).

The objective of the study is to analyse the environmental impacts of farmer's crop choice when there are externalities in arable plant production. These environmental externalities lead to an inefficient allocation of arable land and use of other inputs, since private valuations of inputs and outputs are different from their social valuations.

We introduce a simple static theoretical model of two crops and two environmental externalities, find the private and social optima of arable land allocation and herbicide use, and use policy instruments to internalise externalities that arise in cultivation of arable crops.

\section{Simple model of arable land allocation and herbicide use}

Let us analyse farmer's short-run crop choice and input use in a static framework under certainty. The related literature includes Boisvert (2001) in which two agricultural commodities were produced along with landscape amenities and an environmental residual. Furthermore, Di Falco and Perrings (2003) analysed farmers' crop choices under uncertainty in a dynamic framework.

We assume that the farmer has a fixed amount of homogenous agricultural land, which he or she allocates between two cereal crops. Crop 1 is rye and crop 2 refers to spring wheat. Let us denote the area devoted to crop 1 by $a_{1}$ and the area devoted to crop 2 by $a_{2}$. For simplicity, we scale the total amount of agricultural land to be 1, i.e. $a_{1}+a_{2}=1$. Furthermore, we postulate that the farmer operates in competitive product and factor markets. We denote the market price of crop 1 by $p_{1}$, the market price of crop 2 by $p_{2}$, the amount of herbicide used by $h$ and the unit price of herbicide by $p_{h}$.

The production function of crop 1, $y_{1}=f\left(a_{1}\right)$, is assumed to be strictly concave: $d y_{1} / d a_{1} \equiv f_{a 1}\left(a_{1}\right)>$ 0 and $f_{a 1 a 1}\left(a_{1}\right)<0$. It is also assumed that production of crop 1 does not require the use of herbicide input. In addition, we presume that the cultivation of crop 1 has some positive environmental effects. More specifically, we assume here that an increase in the amount of land under crop 1 boosts the output of crop 2. The rationale behind this external economy is a decrease in pests, diseases and weeds as a result of more diverse arable land use, so that productivity of crop 2 is greater when the amount of $a_{1}$ is higher. As the production function of crop 2 is $y_{2}=g\left(a_{2}, a_{1}, h\right)$, the above assumption means formally that $\partial y_{2} / \partial a_{1} \equiv$ $g_{a 1}\left(a_{2}, a_{1}, h\right)>0$. Furthermore, the marginal product of land input $a_{1}$ is assumed to be diminishing, i.e.

$\frac{\partial^{2} y_{2}}{\partial a_{1}^{2}} \equiv g_{a_{1} a_{1}}\left(a_{2}, a_{1}, h\right)<0$

It is also assumed that the marginal products of $a_{2}$ and $h$ are positive and diminishing

$$
\frac{\partial y_{2}}{\partial a_{2}} \equiv g_{a_{2}}(\cdot)>0 \quad \frac{\partial^{2} y_{2}}{\partial a_{2}^{2}} \equiv g_{a_{2} a_{2}}(\cdot)<0
$$


and

$\frac{\partial y_{2}}{\partial h} \equiv g_{h}(\cdot)>0 \quad \frac{\partial^{2} y_{2}}{\partial h^{2}} \equiv g_{h h}(\cdot)<0$

The arable area devoted to production of crop 2 and herbicide use are complements in production

$g_{a_{2} h}(\cdot) \equiv g_{h a_{2}}(\cdot)>0$

i.e. the rate of change of a marginal physical product of one input is positive as the amount of the other input increases.

\section{Private optimum}

Firstly, let us consider the short-run field allocation and herbicide use problem of a representative farmer, when he or she does not realise that cultivation of crop 1 enhances production of crop 2 . This assumption may sound too simplifying or even unrealistic, because we analyse the crop choice of an individual farmer, but it makes perfect sense if there are more farmers involved in the same geographical area. Then the neighbour of an individual farmer may not realise that cultivation of crop 1 enhances his or her neighbour's yield of crop 2 . Therefore we retain the above assumption of an environmental market failure. The production function of crop 2 of which the farmer bases his or her decisions is thus now $y_{2}=g\left(a_{2}, h\right)$ and the profit maximisation problem of the farmer is

$$
\underset{a_{1}, a_{2}, h}{\operatorname{Max}} \pi=p_{1} f\left(a_{1}\right)+p_{2} g\left(a_{2}, h\right)-p_{h} h
$$

s.t. $\quad a_{1}+a_{2}=1$

When we have an interior solution (i.e., it is profitable to cultivate both crops), the farmer's optimum is characterised by

$$
p_{1} f_{a_{1}}\left(a_{1}\right)=p_{2} g_{a_{2}}\left(a_{2}, h\right) \Leftrightarrow \frac{g_{a_{2}}\left(a_{2}, h\right)}{f_{a_{1}}\left(a_{1}\right)}=\frac{p_{1}}{p_{2}}
$$

and

$$
p_{2} g_{h}\left(a_{2}, h\right)=p_{h}
$$

Thus at the farmer's private optimum, when both crops are cultivated, the value of marginal product of arable land devoted to production of crop 1 has to be equal to the value of marginal product of arable land devoted to production of crop 2. Therefore the ratio between marginal physical products of arable land is inversely related to the ratio of crop prices. This is because, if, for example, the price of crop 1 increases, it is profitable for the farmer to increase production of crop 1 . Then the arable area under crop 1 is increased and this increase reduces marginal product of $a_{1}$, since we assumed that the marginal product of $a_{1}$ is diminishing. Furthermore, at the farmer's private optimum, the value of marginal product of herbicide is equal to its price, i.e. its marginal cost.

\section{Command optimum}

A command optimum refers to the socially optimal arable land allocation and input use in the absence of taxes and subsidies. Let us assume that the social welfare function of the society is represented by

$S W=p_{1} f\left(a_{1}\right)+p_{2} g\left(a_{2}, a_{1}, h\right)-p_{h} h-D(h)$

The social welfare function thus includes farmer's profit function when it is known that cultivation of crop 1 enhances production of crop 2 . In addition, the social welfare function also contains damages of herbicides to society (i.e. individuals, animals and plants), denoted by $D(h)$, which is the monetary equivalent of the damages suffered. It is assumed that an increase in the use of herbicide generates 
damages at an increasing rate. Therefore we have $D_{h}(h)>0$ and $D_{h h}(h)>0$.

A social planner may solve the command optimum by maximising the social welfare function subject to arable land constraint $a_{1}+a_{2}=1$. Rearranging the first-order conditions yields the following socially optimal arable land allocation

$$
p_{1} f_{a_{1}}(\cdot)+p_{2} g_{a_{1}}(\cdot)=p_{2} g_{a_{2}}(\cdot) \Leftrightarrow \frac{g_{a_{2}}(\cdot)-g_{a_{1}}(\cdot)}{f_{a_{1}}(\cdot)}=\frac{p_{1}}{p_{2}}
$$

and herbicide use

$$
p_{2} g_{h}(\cdot)-D_{h}(\cdot)=p_{h}
$$

Thus at the command optimum, when both crops are cultivated, the values of marginal products of arable land devoted to each crop have to be equal. Note that the land area devoted to rye, $a_{1}$, affects productivity of both crops. The ratio between marginal products of arable areas is again inversely related to the ratio of crop prices. The left-hand side of the equation represents the negative of the marginal rate of transformation; i.e. the negative of the rate at which the output of crop 2 varies as the output of crop 1 is increased in production. The numerator in the left-hand side includes the externality term $-g_{\mathrm{al}}(\cdot)$, which relieves the decrease in output of crop 2 when the output of crop 1 is increased.

Furthermore, at the socially optimal level of output, the value of marginal product of herbicide used net of the marginal damage done by factor $h$ is equal to its marginal cost, i.e. the unit price of herbicide.

Two interesting questions arise immediately. Namely, do the areas under different crops differ between the private and command optima? And, is the amount of herbicide used smaller at the command optimum?

The answer to the first question is that the area under crop 1 is larger at the social optimum than at the farmer's private optimal solution. This is because at the command optimum, the marginal product of area under crop 1 has to be smaller and the corresponding amount of input used larger than at the private optimum. This can be seen by comparing the first-order conditions of the optimisation problems, i.e. $p_{1} f_{a 1}(\cdot)=\lambda-p_{2} g(\cdot)$ of the command optimum and $p_{1} f_{a 1}(\cdot)=\lambda$ of the private optimum. Since prices, and thus also the shadow price $\lambda$ (i.e. the marginal value of the constraint on arable land), are constant, $f_{a 1}$ at the command optimum has to be smaller than $f_{a 1}$ at the private optimum. This indicates that $a_{1}$ is larger at the command optimum, because we assumed a diminishing marginal product of land input $a_{1}$. Furthermore, the area under crop 2 at the command optimum is smaller than the one at the farmer's private optimum, because $a_{2}=1-a_{1}$.

The answer to the second question is that the amount of herbicide used is smaller at the social optimum than at the farmer's private optimum. This can be proved similarly as above by comparing the necessary conditions of the command and private optima, $p_{2} g_{h}(\cdot)=p_{h}+D_{h}(h)$ and $p_{2} g_{h}(\cdot)=p_{h}$, respectively. Since $D_{h}(h)>0$, we have to have a larger marginal product of herbicide use, $g_{h}(\cdot)$, at the command optimum, and this in turn means the smaller amount of herbicide used, since the marginal product of herbicide use is diminishing.

\section{Internalisation of externalities}

The correction of privately optimal arable land allocation and input the use requires use of policy instruments. Since the farmer does not know or take into account that cultivation of crop 1 has positive environmental effects, the government may subsidise production of crop 1 and impose the crop-specific area payment $s$. The farmer also neglects the social costs originated from herbicide use. The social damages can be internalised by imposing a Pigouvian tax, $t$, to farmer's herbicide use. In the presence of acreage subsidy and environmental tax, the profit-maximisation problem of the farmer becomes

$$
\begin{aligned}
& \underset{a_{1}, a_{2}, h}{\operatorname{Max}} \pi=p_{1} f\left(a_{1}\right)+p_{2} g\left(a_{2}, h\right)+s a_{1}-p_{h} h-t h \\
& \text { s.t. } \quad a_{1}+a_{2}=1
\end{aligned}
$$


The first-order conditions are

$$
\begin{aligned}
& p_{1} f_{a_{1}}(\cdot)+s=p_{2} g_{a_{2}}(\cdot) \\
& p_{2} g_{h}(\cdot)-t=p_{h}
\end{aligned}
$$

By comparing the necessary conditions in the presence of government intervention with the first-order conditions of the command optimum, it is straightforward to see that the level of acreage subsidy, $s$, depends on the value of the marginal product of input $a_{1}$ in production of crop 2 . Therefore, the socially optimal subsidy for the acreage $a_{1}$ has to be equal to $p_{2} g_{\text {a1 }}(\cdot)$. With similar reasoning, the optimal tax rate $t$ has to be equal to marginal social damage of herbicide use at the command optimum, i.e. $D_{h}(h)$.

Since the farmer receives subsidy equal to

$$
s^{*} a_{1}^{*}=p_{2} g_{a_{1}}(\cdot) a_{1}^{*}
$$

and pays taxes the amount of $D_{h}(\cdot) h^{*}$, it is possible that the government expenditures may increase as a result of the internalisation of externalities. Therefore the government may wish to tax farmer in order to receive back the net transfer payments paid.

\section{Conclusions}

The results indicate that the area under rye is larger at the socially optimal solution than at the farmer's private optimum. The herbicide use in turn is smaller at the social optimum. The correction of privately optimal arable land allocation and herbicide use requires the use of policy instruments. The internalisation of positive environmental externalities may be done, for example, by imposing a crop-specific area payment for the area under rye. The social damages of herbicide use can be internalised by levying a tax to farmer's herbicide use.

Since farmland birds are good indicators of the agricultural environment, the next step will be to develop an empirical model and approximate the effects of arable plant production on the environment.

\section{References}

Boisvert, R.N. 2001. Joint production in four outputs: Two agricultural commodities and positive and negative externalities (Annex 2). In: Multifunctionality: Towards an analytical framework. OECD, Paris, pp. 125-132. ISBN: 92-64-18625-5.

Collins, W.W. \& Hawtin, G.C. 1999. Conserving and Using Crop Plant Biodiversity in Agroecosystems. In: Collins, W.W. and Qualset, C.O. (eds.). Biodiversity in Agroecosystems. CRC Press. Boca Raton, FL, USA, pp. $267-$ 282. ISBN: 1-56670-290-9.

Di Falco, S. \& Perrings, C. 2003. Crop genetic diversity, productivity and stability of agroecosystems. A theoretical and empirical investigation. Scottish J. of Pol. Econ. 50: 207-216.

Mukula, J., Raatikainen, M., Lallukka, R.\& Raatikainen, T. 1969. Composition of weed flora in spring cereals in Finland. Ann. Agrig. Fenn. 8: 59-110.

Raatikainen, M. \& Raatikainen, T. 1974. Heinänurmien sato, kasvilajikoostumus ja sen muutokset. Ann. Agrig. Fenn. 14: 57-191.

Raatikainen, M. \& Raatikainen, T. \& Mukula, J. 1978. Weed species, frequencies and densities in winter cereals in Finland. Ann. Agrig. Fenn. 17: 115-142.

Tiainen, J. 1996. Fasaani (Phasianus colchicus). In: Lindén, H., Hario, M. \& Wikman, M. (eds.). Riistan jäljille. Riista- ja kalatalouden tutkimuslaitos, Helsinki, pp. 188-191. ISBN: 951-776-086-8.

Tiainen, J. \& Pakkala, T. 1996. Peltopyy (Perdix perdix). In: Lindén, H., Hario, M. \& Wikman, M. (eds.). Riistan jäljille. Riista- ja kalatalouden tutkimuslaitos, Helsinki, pp. 184-187. ISBN: 951-776-086-8.

Tiainen, J. \& Pankakoski, E. 1996. Rusakko (Lupus europaeus). In: Lindén, H., Hario, M. \& Wikman, M. (eds.). Riistan jäljille. Riista- ja kalatalouden tutkimuslaitos, Helsinki, pp. 20-23. ISBN: 951-776-086-8. 